\title{
Impact of strabismus on the quality of life of Chinese Han teenagers
}

\author{
This article was published in the following Dove Press journal: \\ Patient Preference and Adherence \\ 8 June 2016 \\ Number of times this article has been viewed
}

\section{Changsen Tu \\ Liang Ye \\ Longfei Jiang \\ Yuwen Wang \\ Yingzi Li}

The Eye Hospital of Wenzhou Medical University, School of Ophthalmology and Optometry, Wenzhou Medical University, Wenzhou, People's Republic of China
Correspondence: Yingzi Li The Eye Hospital of Wenzhou Medical University, School of Ophthalmology and Optometry, Wenzhou Medical University, 270 West College Road, 325000 Wenzhou, People's Republic of China

Tel +8657788068888

Email liyingzi_0@163.com
Background: Although much research has been conducted on the impact of strabismus on the quality of life (QoL) of adults, the effect of this condition on teenagers has not been extensively studied. This study therefore aimed to assess the effect of strabismus on the vision-related QoL of Chinese teenagers.

Methods: The Chinese version of the 25-item National Eye Institute Visual Function Questionnaire (NEI-VFQ-25) was self-administered by 1,040 teenagers with strabismus and 1,002 individuals with normal vision. All the participants were from the Chinese Han population. The independent samples $t$-test was used to compare QoL between teenagers with and without strabismus.

Results: The majority of scores on the NEI-VFQ-25 domains were significantly different between the two groups. QoL was significantly lower in individuals with strabismus compared with teenagers with normal vision on all domains, with the exception of social functioning.

Conclusion: Statistically significantly lower vision-related QoL scores were found in Chinese Han teenagers with strabismus compared with those without strabismus.

Keywords: quality of life, strabismus, NEI-VFQ-25, teenager, HRQoL

\section{Background}

Despite the increasing number of studies focusing on the treatment of strabismus, there is little robust evidence regarding the vision-related quality of life (QoL) of individuals with this condition or the impact of strabismus treatment on the QoL of patients. The World Health Organization (WHO) defines health-related QoL (HRQoL) as an "individuals' perception of their position in life in the context of the culture and value systems in which they live and in relation to their goals, expectations, standards and concerns". ${ }^{1}$ Today, individuals care not only about the effectiveness of a treatment but also about the effect the treatment will have on their QoL. Questionnaires that measure QoL are important tools in assessing patients' psychological well-being, pain, social function, and physical health. More research is now being conducted into visionrelated QoL, ${ }^{2}$ and QoL questionnaires have been designed to examine vision-related pain, social function, and psychosocial status in various eye diseases..$^{3-7}$ However, the impact of strabismus on HRQoL has not been adequately explored.

Strabismus has an incidence of $\sim 10 \%$ in the general population. ${ }^{6}$ Its presence can have a profound impact on teenagers due to visual dysfunction, lack of confidence, and social and emotional barriers, all of which can decrease HRQoL. ${ }^{6,7}$ In addition, the appearance of misaligned eyes in strabismus patients can result in social discrimination. ${ }^{8,9}$ Several studies have assessed the impact of strabismus on the QoL of adult patients. ${ }^{7,10}$ However, there is little literature on the impact of this condition on 
the HRQoL of teenagers. ${ }^{6-9}$ Most studies to date have found that strabismus reduces QoL. However, these studies have used different questionnaires than those used in the current study and were conducted in different countries. Furthermore, most of these studies included only small numbers of participants.

Several questionnaires have been designed to assess the QoL of patients with eye diseases, including the Amblyopia and Strabismus Questionnaire, the Amblyopia Treatment Index, and the 25-Item National Eye Institute Visual Function Questionnaire (NEI-VFQ-25). ${ }^{5-7,11}$ The NEI-VFQ-25 is one of the most widely used vision-specific instruments. ${ }^{11}$ It contains 12 domains, which are as follows: distance activities, vision-specific domains, color vision, general vision, near activities, general health, ocular pain, peripheral vision, and driving. The scores range from 0 to 100 for each item. The total score is calculated as the average of all items responded to, with the exception of the "general health" question, which is treated as a stand-alone item. Because different people from different countries can vary in both their understanding and expression of vision-related QoL, it is important to take ethnicity into consideration. ${ }^{12}$ Therefore, we used a Chinese version of the NEI-VFQ-25 to assess the vision-related QoL of Chinese strabismus patients.

Thus, the aim of this study was to assess the impact of strabismus on the vision-related QoL of Chinese teenagers, using the Chinese version of the NEI-VFQ-25.

\section{Methods}

\section{Ethical considerations}

The Human Ethics Committee of the Eye Hospital at Wenzhou Medical University approved this trial. All participants were given a verbal and written explanation of the study, and no personal information was recorded during the trial. All participants provided written informed consent. The patients with strabismus were assured that the results of the survey would not influence their treatment. This study was conducted in accordance with the Declaration of Helsinki.

\section{Participants}

The sample size for each group was calculated based on an alpha significance level of 0.05 and a beta significance level of 0.1 to achieve $90 \%$ power to detect a clinically meaningful difference between the two groups. The power analysis showed that 568 patients should be recruited in each group.

A total of 1,060 teenagers with a diagnosis of strabismus were recruited from the Eye Hospital at Wenzhou Medical University. Individuals with other eye diseases, systematic disease, mental health problems, or other health problems were excluded. Twenty patients failed to complete the questionnaire, giving a high response rate of $98 \%$.

A total of 1,002 teenagers with normal vision were recruited from a local high school and formed the control group. Individuals with a history of eye disease, surgery, or other severe health problems were excluded from the study. All the participants in both groups were from the Chinese Han population.

\section{Data collection}

For the strabismus group, questionnaires were completed at the hospital and immediately returned. For the control group, questionnaires were completed in the classroom and again immediately returned.

In order to ensure that participants understood the questionnaire, the same researcher remained in the examination room or classroom in order to clarify any items that the participants did not understand.

\section{Statistical analysis}

Simple descriptive statistics have been used to show the baseline information for the two groups. The chi-square and independent samples $t$-test were used to compare QoL scores between the two groups. The $P$-value was set to $<0.05$. All data were analyzed using SPSS Version 20.0 (IBM Corporation, Armonk, NY, USA).

\section{Results}

\section{Demographic characteristics}

The baseline characteristics of the two groups are shown in Table 1 . There were no statistically significant differences between the two groups in their baseline information.

Table I Overview of the demographic features of participants with $(n=I, 040)$ and without $(n=I, 002)$ strabismus

\begin{tabular}{|c|c|c|c|}
\hline Variable & $\begin{array}{l}\text { Participants with } \\
\text { strabismus }\end{array}$ & $\begin{array}{l}\text { Normal-vision } \\
\text { participants }\end{array}$ & $P$-value \\
\hline Male, $n$ & 480 & 460 & NS \\
\hline $\begin{array}{l}\text { Age (years), } \\
\text { mean } \pm S D\end{array}$ & $15.6 \pm 1.2$ & $15.8 \pm 1.3$ & NS \\
\hline \multicolumn{4}{|c|}{ Family support, $\mathrm{n}$} \\
\hline Never & 210 & 189 & \\
\hline Sometimes & 420 & 402 & \\
\hline Always & 410 & 411 & NS \\
\hline \multicolumn{4}{|c|}{ Socioeconomic status, $\mathrm{n}$} \\
\hline High income & 502 & 483 & \\
\hline Low income & 538 & 519 & NS \\
\hline
\end{tabular}

Abbreviations: NS, not significant; SD, standard deviation. 
Table 2 Mean scores for teenagers with $(n=I, 040)$ and without $(n=I, 002)$ strabismus on the NEI-VFQ-25

\begin{tabular}{|c|c|c|c|c|c|}
\hline \multirow[t]{2}{*}{ Domain } & \multicolumn{2}{|c|}{ Normal vision } & \multicolumn{2}{|c|}{ Strabismus } & \multirow[t]{2}{*}{$P$-value } \\
\hline & Mean & SD & Mean & SD & \\
\hline General health & 75.5 & 6.5 & 60.4 & 8.1 & $0.001 *$ \\
\hline General vision & 92.3 & 8.4 & 78.6 & 8.5 & $0.001 *$ \\
\hline Ocular pain & 95.5 & 7.5 & 82.3 & 8.8 & $0.001 *$ \\
\hline Near activities & 92.4 & 8.5 & 84.9 & 7.8 & $0.026 * *$ \\
\hline Distance activities & 93.6 & 9.4 & 81.8 & 8.8 & $0.001 *$ \\
\hline Vision specific & 92.3 & 8.4 & 81.2 & 8.4 & $0.038 * *$ \\
\hline Social functioning & 92.4 & 7.8 & 90.3 & 8.4 & NS \\
\hline Mental health & 93.5 & 6.9 & 85.6 & 7.8 & $0.046 * *$ \\
\hline Role difficulties & 88.6 & 9.1 & 80.7 & 6.7 & $0.039 * *$ \\
\hline Dependency & 91.3 & 4.6 & 82.6 & 5.6 & $0.001 *$ \\
\hline Driving & 92.3 & 5.4 & 83.5 & 6.2 & $0.015^{* *}$ \\
\hline Color vision & 92.6 & 8.1 & 82.5 & 7.9 & $0.00 I^{*}$ \\
\hline Peripheral vision & 93.5 & 7.8 & 82.1 & 8.6 & $0.001^{*}$ \\
\hline Total score & 90.5 & 6.8 & 79.9 & 8.1 & $0.001 *$ \\
\hline
\end{tabular}

Note: $* P<0.01$ and $* * P<0.05$

Abbreviations: NEI-VFQ-25, 25-Item National Eye Institute Visual Function Questionnaire; SD, standard deviation; NS, not significant.

\section{Results of QoL}

A total of 2,042 valid questionnaires were available for statistical analysis. The QoL scores were significantly lower (ie, worse QoL) in the strabismus group compared with the normal-vision group for all domains, with the single exception of social functioning (Table 2). The score differences between the two groups ranged from $\sim 8$ to 15 points.

\section{Discussion}

There is no vision-specific instrument for assessing HRQoL in a population-based sample of teenagers. To the best of our knowledge, this is one of the first studies to explore issues of HRQoL in association with strabismus in a teenage population in the People's Republic of China. In the present study, we found that QoL scores were lower among teenagers with strabismus compared with those with normal vision across most domains of the NEI-VFQ-25.

Significant strengths of our study are the large sample of teenagers and the high response rate. Our study included $>2,000$ participants, which is more than any previous studies. In addition, the high response rate makes it likely that our findings are representative of all teenagers and may be applicable to other strabismus patients.

We found a negative impact of strabismus on an individual's HRQoL, which is consistent with earlier studies. ${ }^{13-16}$ Previous studies have assessed the impact of strabismus on both adults and children. They found that strabismus plays an important role in selecting a partner for adults and in selecting a playmate for children. ${ }^{13,14}$ It has also been reported, using other questionnaires, such as the Hospital Anxiety and Depression Scale and the WHO QoL measure, that strabismus causes patients to feel embarrassed and that patients' psychological and physical functioning can be significantly improved following treatment. ${ }^{15}$

In the present study, we also found that teenagers with strabismus showed lower QoL scores on function-related items than on those related to psychosocial effects. However, others have reported that adult patients are more concerned about psychosocial impacts rather than functional items. ${ }^{17}$ It might be that double vision, for example, leads to feelings of tension and anxiety; in addition, function might be more important than psychosocial effects to teenagers. Therefore, ophthalmologists and nurses should pay attention not only to daily visual function but also to psychosocial concerns in teenage strabismus patients.

It is interesting that, in the present study, social function did not significantly differ between the two groups. Manifest strabismus might be expected to result in a negative social bias and teasing in teenagers. ${ }^{18,19}$ Nevertheless, some previous studies have shown a surprising lack of teasing and bullying of children with strabismus. ${ }^{20,21}$ It is also possible that because teenagers with strabismus are mostly able to control exodeviation at conversational distances, the exodeviation goes largely unnoticed by peers. Another reason might be the inclusion of only teenage patients in our study; it might be that their social influence is still developing and that this effect might be different over time.

The results of this study with respect to the influence of strabismus on QoL in teenage patients are consistent with those from previous studies. Generally speaking, it would be better to conduct patient-derived instruments when we create or improve vision-related questionnaires; however, most of the previous studies that have looked at the influence of strabismus on QoL have not used patient-derived questionnaires. ${ }^{21-26}$ A QoL questionnaire based on a patientderived instrument is thought to be more appropriate than one purely based on a researcher's or clinician's opinion. ${ }^{27-29}$ Thus, in future studies, we need to further investigate the use of patient-derived, condition-specific QoL questionnaires compared with patient-derived, generic questionnaires, such as in the present study.

The main drawback of our analysis is our heavy reliance on a generalized HRQoL instrument. At the beginning of the study, there were no tools specifically tailored to evaluate the HRQoL of teenagers with eye diseases. In addition, our focus was only on Chinese teenagers, and our findings might not be necessarily applicable to teenagers of other ethnicities. 
More studies should be conducted with individuals of different countries or ethnicities.

\section{Conclusion}

Our results indicated that strabismus could significantly reduce the HRQoL of Chinese teenagers.

\section{Disclosure}

The authors report no conflicts of interest in this work.

\section{References}

1. WHOQOL-Group. The World Health Organization Quality of Life assessment (WHOQOL): position paper from the World Health Organization. Soc Sci Med. 1995;41(10):1403-1409.

2. Samsa G, Edelman D, Rothman ML, Williams GR, Lipscomb J, Matchar D. Determining clinically important differences in health status measures: a general approach with illustration to the Health Utilities Index Mark II. Pharmacoeconomics. 1999;15(2):141-155.

3. Guyatt GH, Feeny DH, Patrick DL. Measuring health-related quality of life. Ann Intern Med. 1993;118(8):622-629.

4. Patrick DL, Deyo RA. Generic and disease-specific measures in assessing health status and quality of life. Med Care. 1989;27(suppl 3): S217-S232.

5. Clarke SA, Eiser C. The measurement of health-related quality of life (QOL) in paediatric clinical trials: a systematic review. Health Qual Life Outcomes. 2004;2:66.

6. Hatt SR, Leske DA, Kirgis PA, Bradley EA, Holmes JM. The effects of strabismus on quality of life in adults. Am J Ophthalmol. 2007;144(5): 643-647.

7. Menon V, Saha J, Tandon R, Mehta M, Khokhar S. Study of the psychosocial aspects of strabismus. J Pediatr Ophthalmol Strabismus. 2002;39(4):203-208.

8. Olitsky SE, Sudesh S, Graziano A, Hamblen J, Brooks SE, Shaha SH. The negative psychosocial impact of strabismus in adults. $J$ AAPOS. 1999;3(4):209-211.

9. Nelson BA, Gunton KB, Lasker JN, Nelson LB, Drohan LA. The psychosocial aspects of strabismus in teenagers and adults and the impact of surgical correction. J AAPOS. 2008;12(1):72.e1-76.e1.

10. Carlton J, Kaltenthaler E. Health-related quality of life measures (HRQoL) in patients with amblyopia and strabismus: a systematic review. Br J Ophthalmol. 2011;95(3):325-330.

11. Wang CW, Chan CL, Jin HY. Psychometric properties of the Chinese version of the 25-item National Eye Institute Visual Function Questionnaire. Optom Vis Sci. 2008;85(11):1091-1099.

12. Guillemin F, Bombardier C, Beaton D. Cross-cultural adaptation of health-related quality of life measures: literature review and proposed guidelines. J Clin Epidemiol. 1993;46(12):1417-1432.
13. Mojon-Azzi SM, Potnik W, Mojon DS. Opinions of dating agents about strabismic subjects' ability to find a partner. Br J Ophthalmol. 2008;92(6): 765-769.

14. Johns HA, Manny RE, Fern KD, Hu YS. The effect of strabismus on a young child's selection of a playmate. Ophthalmic Physiol Opt. 2005; 25(5):400-407.

15. Buck D, Clarke MP, Powell C, Tiffin P, Drewett RF. Use of the PedsQL in childhood intermittent exotropia: estimates of feasibility, internal consistency reliability and parent-child agreement. Qual Life Res. 2011;10:1007.

16. Felius J, Beauchamp GR, Stager DR Sr, Van De Graaf ES, Simonsz HJ. The amblyopia and strabismus questionnaire: English translation, validation, and subscales. Am J Ophthalmol. 2007;143(2):305-310.

17. Hatt SR, Leske DA, Bradley EA, Cole SR, Holmes JM. Development of a quality-of-life questionnaire for adults with strabismus. Ophthalmology. 2009;116(1):139.e5-144.e5.

18. Paysse EA, Steele EA, McCreery KM, Wilhelmus KR, Coats DK. Age of the emergence of negative attitudes toward strabismus. $J$ AAPOS. 2001;5(6):361-366.

19. Uretman O, Egrilmez S, Kose S, Pamukçu K, Akkin C, Palamar M. Negative social bias against children with strabismus. Acta Ophthalmol Scand. 2003;81(2):138-142.

20. Horwood J, Waylen A, Herrick D, Williams C, Wolke D. Common visual defects and peer victimization in children. Invest Ophthalmol Vis Sci. 2005;46(4):1177-1181.

21. Burke J, Leach C, Davis H. Psychosocial implications of strabismus surgery in adults. J Pediatr Ophthalmol Strabismus. 1997;34(3): 159-164.

22. Satterfield D, Keltner J, Morrison T. Psychosocial aspects of strabismus study. Arch Opthalmol. 1993;111(8):1100-1105.

23. Beauchamp G, Black B, Coats D, et al. The management of strabismus in adults - III. The effects on disability. J AAPOS. 2005;9(5):455-459.

24. van de Graaf E, van der Sterre G, Polling J, et al. Amblyopia \& strabismus questionnaire: design and initial validation. Strabismus. 2004; 12(3):181-193.

25. Jackson S, Harrad R, Morris M, Rumsey N. The psychosocial benefits of corrective surgery for adults with strabismus. Br JOphthalmol. 2006; 90(7):883-888.

26. McKeon C, Wick B, Aday L, Begley C. A case-comparison of intermittent exotropia and quality of life measurements. Optom Vis Sci. 1997; 74(2):105-110.

27. Margolis MK, Coyne K, Kennedy-Martin T, et al. Vision-specific instruments for the assessment of health-related quality of life and visual functioning. Pharmacoeconomics. 2002;20(12):791-812.

28. Calman KC. Quality of life in cancer patients - an hypothesis. J Med Ethics. 1984;10(3):124-127.

29. Guyatt GH, Bombardier C, Tugwell P. Measuring disease-specific quality of life in clinical trials. Can Med Assoc J. 1986;134(8):889-895.
Patient Preference and Adherence

\section{Publish your work in this journal}

Patient Preference and Adherence is an international, peer-reviewed, open access journal that focuses on the growing importance of patient preference and adherence throughout the therapeutic continuum. Patient satisfaction, acceptability, quality of life, compliance, persistence and their role in developing new therapeutic modalities and compounds to optimize

\section{Dovepress}

clinical outcomes for existing disease states are major areas of interest for the journal. This journal has been accepted for indexing on PubMed Central. The manuscript management system is completely online and includes a very quick and fair peer-review system, which is all easy to use. Visit http://www. dovepress.com/testimonials.php to read real quotes from published authors. 